\title{
AT CASTERBRIDGE FAIR
}

THE BALLAD-SINGER

SiNG, Ballad-singer, raise a hearty tune; Make me forget that there was ever a one I walked with in the meek light of the moon When the day's work was done.

Rhyme, Ballad-rhymer, start a country song; Make me forget that she whom I loved well Swore she would love me dearly, love me long, Then - what I cannot tell!

Sing, Ballad-singer, from your little book; Make me forget those heart-breaks, achings, fears; Make me forget her name, her sweet sweet look Make me forget her tears.

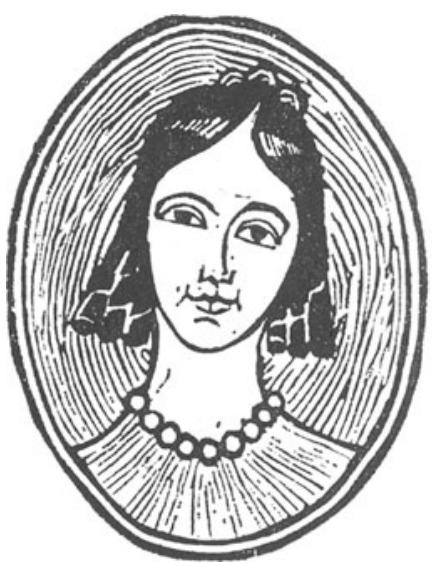

